\title{
Essential Contributions of Serotonin Transporter Inhibition to the Acute and Chronic Actions of Fluoxetine and Citalopram in the SERT Met 72 Mouse
}

\author{
Alex G Nackenoff', Alexandra B Moussa-Tooks', Austin M McMeekin', Jeremy Veenstra-VanderWeele ${ }^{3}$ and \\ Randy D Blakely*,1,2 \\ 'Department of Pharmacology, Vanderbilt University School of Medicine, Nashville, TN, USA; ${ }^{2}$ Department of Psychiatry, Vanderbilt University \\ School of Medicine, Nashville, TN, USA; ${ }^{3}$ Department of Psychiatry, Columbia University College of Physicians and Surgeons/New York Psychiatric \\ Institute, New York, NY, USA
}

\begin{abstract}
Depression is a common mental illness and a leading cause of disability. The most widely prescribed antidepressant medications are serotonin (5-HT) selective reuptake inhibitors (SSRIs). Although there is much support for 5 -HT transporter (SERT) antagonism as a basis of antidepressant efficacy, this evidence is indirect and other targets and mechanisms have been proposed. In order to distinguish SERTdependent and -independent effects of SSRIs, we developed a knock-in mouse model whereby high-affinity interactions of many antidepressants at SERT have been ablated via knock-in substitution (SERT Met I72) without disrupting 5-HT recognition or uptake. Here we utilize the C57BL/6) SERT Met I 72 model to evaluate SERT dependence for the actions of two widely prescribed SSRIs, fluoxetine and citalopram, in tests sensitive to acute and chronic actions of antidepressants. In the tail suspension and forced swim tests, fluoxetine and citalopram fail to reduce immobility in SERT Met I 72 mice. In addition, SERT Met 172 mice are insensitive to chronic fluoxetine and citalopram administration in the novelty induced hypophagia test $(\mathrm{NIH})$ and fail to exhibit enhanced proliferation or survival of hippocampal stem cells. In both acute and chronic studies, SERT Met I 72 mice maintained sensitivity to paroxetine, an antidepressant that is unaffected by the Met 72 mutation. Together, these studies provide definitive support for an essential role of SERT antagonism in the acute and chronic actions of two commonly used SSRIs in these tests, and reinforce the utility of the SERT Met I72 model for isolating SERT/5-HT contributions of drug actions in vivo.
\end{abstract}

Neuropsychopharmacology (2016) 4I, I733-I74I; doi:I0. I038/npp.2015.335; published online 25 November 2015

\section{INTRODUCTION}

Depression is a common psychological disorder that affects $\sim 7 \%$ of the US population (Kessler et al, 2005), with lifetime prevalence approaching 17\% (Kessler, 2005). The presynaptic serotonin (5-HT) transporter (SERT) is critical for terminating 5-HT signaling, and changes in SERT expression and/or activity have been proposed to underlie multiple behavioral disorders including depression, obsessive compulsive disorder, and autism (Arango et al, 1995; Malison et al, 1998; Mann et al, 2000; Owens and Nemeroff, 1994; Veenstra-VanderWeele et al, 2012; Ye and Blakely, 2011). Polymorphisms in the SERT promoter region have been reported to influence SERT gene and protein expression (Lesch et al, 1996) and influence sensitivity to life stressors, suggesting a gene-by-environment interaction

\footnotetext{
*Correspondence: Dr RD Blakely, Department of Pharmacology, Vanderbilt University School of Medicine, 7I 40 MRBIII, PMB 407933, Nashville, TN 37240-7933, USA, Tel: +615936 1700, Fax: +615936 3745, E-mail: randy.blakely@vanderbilt.edu

Received 7 September 2015; revised 20 October 2015; accepted 27 October 2015; accepted article preview online 30 October 2015
}

(Caspi et al, 2003). The 5-HT selective reuptake inhibitors (SSRIs), which antagonize SERT and prolong in vivo 5-HT clearance, are the most common class of antidepressant medications. One challenge to the theory that 5-HT reuptake blockade solely mediates the antidepressant efficacy of SSRIs is that in vivo SERT antagonism occurs within minutes of SSRI administration, whereas therapeutic efficacy requires 4-6 weeks of treatment. Although such a difference can be reconciled through the consideration of time-dependent plasticities arising as a consequence of sustained SERT antagonism, SSRIs have been found to engage other targets that could also contribute to efficacy (Bianchi, 2008; Owens et al, 1997), particularly considering the CNS drug concentration range $(1-10 \mu \mathrm{M})$ needed for therapeutic effect (Karson et al, 1993; Meyer et al, 2004). These targets include $\mathrm{K}^{+}, \mathrm{Na}^{+}$, and $\mathrm{Ca}^{++}$channels (for review, see Bianchi, 2008), GABA-A (Robinson et al, 2003), nACh (García-Colunga et al, 1997), $\sigma$-1 (Villard et al, 2011), and 5-HT receptors (Owens et al, 1997). Elucidating a role for these targets in SSRI action is presumed to inform the development of medications with an improved side-effect profile, though several have been proposed to also contribute 
to antidepressant action (Heurteaux et al, 2006; Saarelainen et al, 2003; Villard et al, 2011).

SERT knockout mice are an obvious choice as a tool for elucidating SERT-dependent and -independent effects of SSRIs. These mice, however, display major molecular and behavioral compensations, notably displaying spontaneous depression-like phenotypes in various behavioral assays (Lira et al, 2003), reduced CNS 5-HT (Bengel et al, 1998), 5-HT neuron number (Lira et al, 2003), changes in 5-HT receptor expression (Cour et al, 2001; Fabre et al, 2000; Li et al, 2000; Rioux et al, 1999), and abnormal dorsal raphe firing rates (Lira et al, 2003). These aberrations in normal anatomy, physiology, and behavior make it difficult to attribute the effects of SSRIs to a loss of SERT activity per se. In order to better understand the direct and indirect effects of SERT targeted drugs, we sought to create an in vivo model wherein SERT drug recognition is perturbed without compromising SERT surface expression and 5-HT transport. We had observed that human and Drosophila melanogaster SERT (hSERT and dSERT, respectively) display markedly different sensitivities to most SSRIs, though they exhibit equivalent 5-HT recognition. Using cross-species chimera and site-directed mutagenesis methods, we established that high-affinity antagonist recognition depends on a single residue near the 5-HT-binding site (Ile172 in human and mouse, Met167 in fly) (Henry et al, 2006). Site-directed mutagenesis studies revealed that a Met172 substitution in either human or mouse SERT reduces potency for many (but not all, eg, paroxtine) SERT antagonists without affecting the interactions of 5-HT or other substrates (Henry et al, 2006). These in vitro studies encouraged our subsequent creation of the SERT Met172 knock-in mouse (Thompson et al, 2011), whose analysis revealed a loss of SSRI-induced prolongation of 5-HT clearance in vivo, accompanied by a failure to elevate extracellular 5 -HT.

Although in the latter studies, we obtained evidence consistent with SERT antagonism as contributing to the acute behavioral actions of SSRIs, the background strain of these mice (129S6/S4) resulted in pro-depressive drug action or inadequate effect sizes to support strong conclusions (Thompson et al, 2011). In order to overcome these issues, and to extend our work to paradigms that better align with the chronic treatments needed for clinical effects, we sought to move the Met172 allele onto a more suitable genetic background. Here we report the results of both acute and chronic SSRI studies utilizing SERT Met172 mice established as congenic on a C57BL/6J background. Our data provide strong evidence that two of the most widely prescribed SSRIs, fluoxetine and citalopram, require SERT blockade to induce behavioral and cellular changes considered predictive of clinical antidepressant efficacy.

\section{MATERIALS AND METHODS}

\section{Animals}

SERT Met172 knock-in mice on a 129S6/S4 background were created as described previously (Thompson et al, 2011). To move to a background more conducive for the study of SSRI sensitivity (Crowley et al, 2005; Gingrich and Hen, 2000; Jacobson and Cryan, 2007; Lucki et al, 2001), we backcrossed animals until the SERT Met172 allele was $>99 \%$ congenic onto a C57BL/6J background using a single-nucleotide polymorphism-based speed congenic approach (Jackson Labs, Bar Harbor, Maine, USA). Because the SERT gene (Slc6a4) in the 129 S6 embryonic stem cells used to generate the SERT Met172 knock-in line harbors a functional, two amino-acid difference with the C57BL/6J SERT (129: $\mathrm{E}^{39} \mathrm{R}^{152}$ haplotype; C57: $\mathrm{G}^{39} \mathrm{~K}^{152}$ haplotype; Carneiro et al, 2009), it was also necessary to establish a second backcrossed line where the wild-type (WT) 129 S6 Slc6a4 gene was expressed on a C57BL/6J background, also established as $>99 \%$ congenic. A cross of the latter line with the C57BL6/J SERT Met172 mice yields mice heterozygous for either SERT Ile172 or SERT Met172 (SERT ${ }^{\mathrm{I172} / \mathrm{M} 172}$ ) with both Slc6a4 alleles sharing the $\mathrm{E}^{39} \mathrm{R}^{152}$ haplotype. These heterozygous mice were the parental animals for the homozygous SERT Ile172 (WT) and SERT Met172 mice used in our studies. Initial characterizations of SERT levels, activity, and monoamine homeostasis were performed upon homozygous mice generated from heterozygous breedings. Because SERT levels, 5-HT clearance, raphe 5-HT neuron firing rates, growth rates, and basal tail suspension test (TST) and forced swim test (FST) behaviors were found to be equivalent in heterozygous bred SERT Ile172 and Met172 animals on both the 129S6/S4 (Thompson et al, 2011) and C57BL/6J backgrounds (these studies) we performed chronic drug treatment studies on WT and SERT Met172 mice generated from homozygous breedings. All animal studies were performed in accordance with protocols approved by the Vanderbilt University Animal Care and Use Committee.

\section{Drugs}

All general biochemical reagents were obtained from SigmaAldrich (St Louis, MO, USA) unless otherwise noted, and were of the highest grade available. Fluoxetine $\mathrm{HCl}$, citalopram $\mathrm{HBr}$, and paroxetine $\mathrm{HCl}$ were acquired from TCI Chemicals (Portland, OR, USA). Before i.p. injections and subsequent acute behavioral studies, drugs were prepared fresh in $0.9 \%$ sterile saline and filtered for sterility (Nalgene syringe filter, $0.2 \mu \mathrm{m}, 195-2520$, ThermoFisher Scientific; Waltham, MA, USA). For chronic administration studies, drugs were dissolved in tap water and filtered for sterility (Stericup-HV, $0.45 \mu \mathrm{m}$, PVDF; SCHVU05RE, Millipore, Billerica, MA, USA). Drinking rates were monitored and found to be unaffected between genotypes or by drug treatments (data not shown).

\section{Quantitation of SERT Protein}

Following killing by rapid decapitation, brain tissue from 8-week-old male mice was dissected and subjected to western blotting analysis for SERT protein. Samples were resolved on $10 \%$ gels by SDS-PAGE, gels were transferred overnight to PVDF membrane (Immobilon, IPVH00010, Millipore), and then SERT was probed using guinea pig anti-SERT primary antibody (Frontier, 5HTT-GP-Af1400, $1: 1000$; Japan; $24 \mathrm{~h}$ at $\left.4{ }^{\circ} \mathrm{C}\right)$ and rabbit anti-guinea pig $(1: 10000$; A-5545, Sigma; $1 \mathrm{~h}$ at room temperature) as secondary antibody. Bands were detected by enhanced chemiluminescence (Clarity ECL substrate, Bio-Rad, Hercules, CA, USA). Membranes were stripped and loading was normalized after probing for mouse anti- $\beta$-actin (Sigma-Aldrich, A5441, $1: 10000 ; 1 \mathrm{~h}$ at 
room temperature) and goat anti-mouse secondary antibody (1: 10 000; 115-035-062, Jackson ImmunoResearch, West Grove, PA, USA; $1 \mathrm{~h}$ at room temperature). Blots were scanned and band density was quantified using ImageJ (http://imagej.nih.gov/ij/).

\section{Brain Monoamine Levels}

Male mice ( 8 weeks) were killed by rapid decapitation and brain regions were dissected on ice and then rapidly frozen on ethanol/dry ice and stored at $-80^{\circ} \mathrm{C}$ until extraction for assessment of monoamine neurotransmitters and metabolites. Monoamine levels were determined by HPLC/EC methods as described previously (Thompson et al, 2011) in the Vanderbilt Brain Institute Neurochemistry Core. Metabolite levels were normalized to tissue extract protein concentration (Pierce BCA, \#23225; ThermoFisher Scientific).

\section{Synaptosomal 5-HT Uptake}

Following killing via rapid decapitation, the midbrains of 8-12-week-old male mice were dissected on ice and used for synaptosomal preparations as described previously (Thompson et al, 2011). For competition uptake assays, equal volumes of synaptosomes were incubated with $20 \mathrm{nM}$ $\left[{ }^{3} \mathrm{H}\right] 5-\mathrm{HT}$ (PerkinElmer, NET498001MC, Waltham, MA, USA) and varying concentrations of inhibitors and incubated at $37^{\circ} \mathrm{C}$ for $10 \mathrm{~min}$. For saturation uptake assays, synaptosomes were prepared using whole brain. Synaptosomes were incubated at $37^{\circ} \mathrm{C}$ for $5 \mathrm{~min}$ with serial dilutions of $5-\mathrm{HT}$ stock containing $10 \%\left[{ }^{3} \mathrm{H}\right] 5-\mathrm{HT}$. At each concentration of $5-\mathrm{HT}$, parallel samples were incubated in the presence of $1 \mu \mathrm{M}$ paroxetine, defining non-specific uptake, which was subtracted from total counts to yield specific uptake. Synaptosomes were assessed for protein concentration for the normalization of 5-HT levels across experiments (Pierce BCA; ThermoFisher).

\section{Behavioral Studies}

All behavioral assays were performed upon behaviorally naive 8-12-week-old male mice in the Neurobehavioral Core $\mathrm{lab}$ at the Vanderbilt University Medical Center. Animals were held at 12-h light:dark cycle (light cycle: 0700 to 1900 hours), and all experimentation occurred between 1300 and 1800 hours. Animals were transferred to housing within the facility and allowed to acclimate for at least 1 week before behavioral manipulations. For acute drug studies, animals were acclimated to handling the day before experimentation, at which point body weight was measured for drug dosing considerations. All drugs for acute drug studies were prepared fresh and administered in $0.9 \%$ sterile saline solution at $20 \mathrm{mg} / \mathrm{kg}(10 \mu \mathrm{l} / \mathrm{g}$ body weight). This dose was utilized to match our prior studies where we demonstrated significant functional SERT occupancy in vivo in WT, but not Met172 mice (Thompson et al, 2011), as assessed by microdialysis studies, and representing a relatively high behaviorally relevant dose (Crowley et al, 2005), which would maximize the potential to detect off-target effects. All experiments and data analyses were scored manually and performed blind to drug condition and genotype.
Tail suspension test. Mice were injected (i.p.) with saline vehicle, fluoxetine, citalopram, or paroxetine $30 \mathrm{~min}$ before a 6-min TST. Mice were then suspended by taping the tail to a vertical aluminum bar and activity was recorded by video. Immobility was quantified as the time when mice are motionless, excluding minute limb movements.

Forced swim test. Mice were injected (i.p.) with saline vehicle, fluoxetine, citalopram, or paroxetine $30 \mathrm{~min}$ before a 6 -min FST. Mice were placed in the center of a $15-\mathrm{cm}$ diameter clear plexiglass cylinder filled with tap water $\left(25-27^{\circ} \mathrm{C}\right)$ to a depth of $\sim 15 \mathrm{~cm}$ for the $6 \mathrm{~min}$ FST and activity was recorded by video. Immobility was quantified as the time when mice floated or only made movements to maintain balance.

Novelty induced hypophagia. Animals were trained to consume a palatable substance (Vanilla Ensure) in their home cage under low red light conditions ( $\sim 50$ lumens) in the testing room for a total of 3 days of 30-min sessions. On the first day of testing, mice were moved to a novel cage with no bedding and high white light illumination ( 1200 lumens), where the latency to first consume Vanilla Ensure, as well as the amount consumed after $30 \mathrm{~min}$ (in grams), were measured. On the following day, latency and consumption values of Vanilla Ensure were assessed in the home cage under low light. To avoid ordering effects, the two testing days were switched for half of the mice. We administered citalopram, fluoxetine, or paroxetine in the drinking water $(160 \mathrm{mg} / \mathrm{l})$ for 28 days before behavioral screening, which was designed to accomplish a $\sim 20 \mathrm{mg} / \mathrm{kg}$-day chronic dosing regimen (David et al, 2009; Santarelli et al, 2003; Warner-Schmidt et al, 2011). Drug dosage was chosen for continuity with the acute drug sensitivity studies described above, as well as producing drug serum concentrations that are on the high end of clinically relevant serum concentrations (Dulawa and Hen, 2005), maximizing the potential to detect off-target activity. Animals were singly housed during training and testing phases.

\section{Hippocampal Neurogenesis}

Proliferation. Following chronic administration of SSRIs and behavioral screening in the NIH test, mice were assayed for levels of hippocampal stem cell proliferation. Mice were administered 5-bromo-2'-deoxyuridine (BrdU; $4 \times 75 \mathrm{mg} / \mathrm{kg}$ i.p., every $2 \mathrm{~h}$; Sigma-Aldrich) to pulse label newly proliferating S-phase mitotic cells $\sim 24 \mathrm{~h}$ following the last behavioral test. Mice continued consumption of water delivered antidepressants up through the BrdU injections. Twenty-four hours following the last injection of BrdU, mice were anesthetized via injection of $100 \mathrm{mg} / \mathrm{kg}$ i.p. pentobarbital and transcardially perfused with ice-cold PBS, followed by ice-cold $4 \%$ paraformaldehyde. Brains were sectioned $(40 \mu \mathrm{m})$ via freezing stage sliding microtome (Leica, SM2000R, Buffalo Grove, IL, USA). Every sixth section of the hippocampus (plates 41-61 (Paxinos and Franklin, 2004)) was immunostained for BrdU incorporation (mouse anti-BrdU; 1:1000; BD\#347580; BD Biosciences; Franklin Lakes, NJ, USA; $48 \mathrm{~h}$ at $4{ }^{\circ} \mathrm{C}$ ) and detected following 
secondary antibody incubation (biotinylated donkey antimouse; 1:500; PA1-28627; ThermoFisher; $2 \mathrm{~h}$ at room temperature), $\mathrm{ABC}$ amplification (VectaStain; Vector Labs; Burlingame, CA, USA; $1 \mathrm{~h}$ at room temperature), and diaminobenzidine detection. Bright-field stitched images were captured (Zeiss Axio Imager.M2) and stored for analysis. BrdU+ cells in both sides of the subgranular zone (SGZ) of the dorsal and ventral hippocampus were counted using the ITCN (Image-based Tool for Counting Nuclei) plugin for ImageJ (Byun et al, 2006) by an observer blinded to genotype and drug treatment. Total number of proliferating stem cells was estimated based on counts obtained in every sixth section (yielding, on average, eight sections/ mouse) and the total number of sections encompassing the hippocampus.

Survival. We injected a separate cohort of mice not used for behavioral experimentation with BrdU prior to administration of SSRIs. Proliferating cells at steady state were pulse labeled with BrdU $(4 \times 75 \mathrm{mg} / \mathrm{kg}$ i.p., every $2 \mathrm{~h})$, and then their drinking water was supplanted with SSRI-infused drinking water (at $160 \mathrm{mg} / \mathrm{l}$ ) $24 \mathrm{~h}$ after the last BrdU injection. After 4 weeks of SSRI administration, mice were killed and brain tissue collected and developed using the immunohistochemistry procedures described above. BrdU+ cell quantification for proliferation measures included the SGZ and the granule cell layer of the dentate. Cell counting was performed as described above.

\section{Graphical and Statistical Methods}

All data were graphed and subjected to statistical analyses using Prism 6.0 (GraphPad, Inc., La Jolla, CA). In all statistical tests, $P$-value significance thresholds were set to $\alpha=0.05$. Specific statistical tests to assess main effects and post hoc tests, as well as $N$ for all groups are provided in the figure legends.

\section{RESULTS}

\section{SERT Met172 Mice Display Normal SERT Expression, Monoamine Levels, and Saturation Uptake Kinetics}

To initiate our studies, we sought to confirm that the SERT Met172 mutation did not alter SERT protein expression, 5-HT recognition, or uptake activity when expressed on a C57BL/6J background. Indeed, quantitative western blot analysis of SERT protein expression revealed no differences in cortical, hippocampal, or midbrain SERT protein levels between WT and SERT Met172 mice (Figure 1a). Similarly, we found no genotype effects on ex vivo 5-HT transport kinetics in whole-brain synaptosomes, neither in 5 -HT $\mathrm{K}_{\mathrm{m}}$ or 5-HT transport $V_{\max }(P>0.05$; Figure $1 \mathrm{~b})$. Last, monoamine neurotransmitter and metabolite levels did not differ between genotypes (Table 1). Together, these data indicate a lack of consequential effects of the SERT Met172 mutant on basal SERT expression and function, as well as monoamine neurotransmitter homeostasis, aligning with our prior studies (Henry et al, 2006; Thompson et al, 2011).

\section{SERT Met172-Derived Synaptosomes Display Reduced Sensitivity to SERT Antagonists}

After confirming normal SERT expression and activity, we sought to verify whether the C57BL/6J backcrossed SERT Met172 allele maintained its reduced sensitivity to specific SERT antagonists (Henry et al, 2006; Thompson et al, 2011). To accomplish this, we performed competitive $\left[{ }^{3} \mathrm{H}\right] 5-\mathrm{HT}$ uptake using midbrain-derived synaptosomes of WT and SERT Met172 mice (Figure 1c). These studies revealed the expected reductions in potency for fluoxetine ( 20 fold $)$ and citalopram ( $\sim 500$ fold) at SERT Met172. In contrast, paroxetine was unaffected by the Met172 mutant, as demonstrated by its equivalent potency of 5-HT uptake inhibition in $\mathrm{WT}$, consistent with predictions from transfected cell studies (Henry et al, 2006).

\section{SERT Met172 Mice are Insensitive to Acute Fluoxetine and Citalopram in the TST and FST}

Having validated the C57BL/6J SERT Met172 model as having normal SERT expression and function, yet disrupted ex vivo sensitivity to the SSRIs fluoxetine and citalopram, we moved to assess the efficacy of these drugs in behavioral assays that are known to be sensitive to acute antidepressant administration (Porsolt et al, 1977; Steru et al, 1985). Clinical antidepressants-including fluoxetine, citalopram, and paroxetine-are known to promote escape-like behavior in mice when presented with an inescapable stressor, such as suspension by the tail (TST) or placement in a cylinder of water (FST). As expected, WT mice showed a robust decrease in immobility following acute fluoxetine and citalopram administration (Figure 2a and $\mathrm{b}$ ), with effect sizes that match those observed in the literature accounting for age, genetic background strain, and drugs utilized (Crowley et al, 2005). SERT Met172 mice, however, displayed no response to either drug (Figure $2 \mathrm{a}$ and $\mathrm{b}$ ). Importantly, paroxetine equivalently suppressed immobility in WT and SERT Met172 mice in both the TST and FST, consistent with the inability of the Met172 substitution to perturb paroxetine interactions. This important control also demonstrates a normal capacity of the SERT Met172 mice to translate SERT inhibition and elevations in extracellular 5-HT into enhanced mobility in both tests.

\section{SERT Met172 Mice Fail to Respond to Chronic Fluoxetine and Citalopram in the NIH Test}

Although the FST and TST are tests with predictive validity for antidepressant efficacy, we sought to evaluate the SERT dependency of SERT actions in the Met172 model using tests that more closely mirror the time course associated with SSRI clinical efficacy. Thus, we implemented the NIH test, a behavioral paradigm sensitive to chronic, but not acute, antidepressant administration (Dulawa and Hen, 2005). The $\mathrm{NIH}$ test involves monitoring the latency of animals to approach and consume a known palatable substance in a novel, stressful environment, where SSRIs reduce latency and enhance consumption after chronic but not acute administration (Dulawa and Hen, 2005). We administered citalopram, fluoxetine, or paroxetine in the drinking water $(160 \mathrm{mg} / \mathrm{l})$ for 28 days before behavioral screening. Following 
SSRI administration, WT mice displayed a reduced latency to consume Vanilla Ensure in the novel cage compared with vehicle condition (Figure 3a), with effect sizes comparable to those reported by others (Dulawa and Hen, 2005; Santarelli et al, 2003). SERT Met172 mice administered paroxetine displayed similar reductions in latency as WT animals, whereas those provided fluoxetine or citalopram showed no significant reductions relative to vehicle condition. Paralleling our findings with latency, WT mice also displayed increased novel cage consumption following all SSRI treatments, whereas SERT Met172 mice displayed increased consumption only with paroxetine administration (Figure $3 \mathrm{~b}$ ).

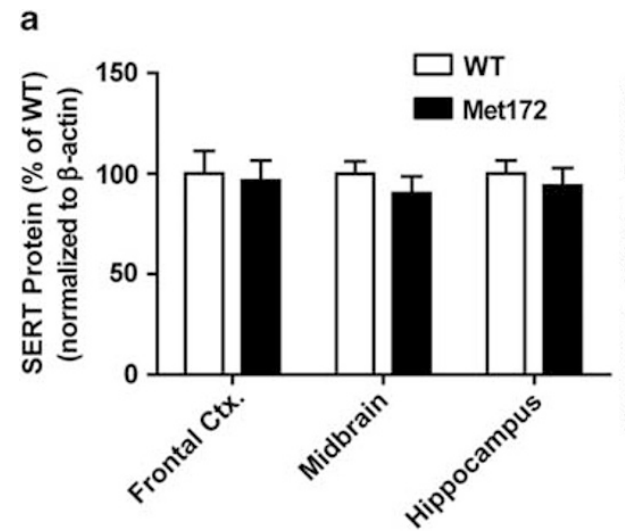

b

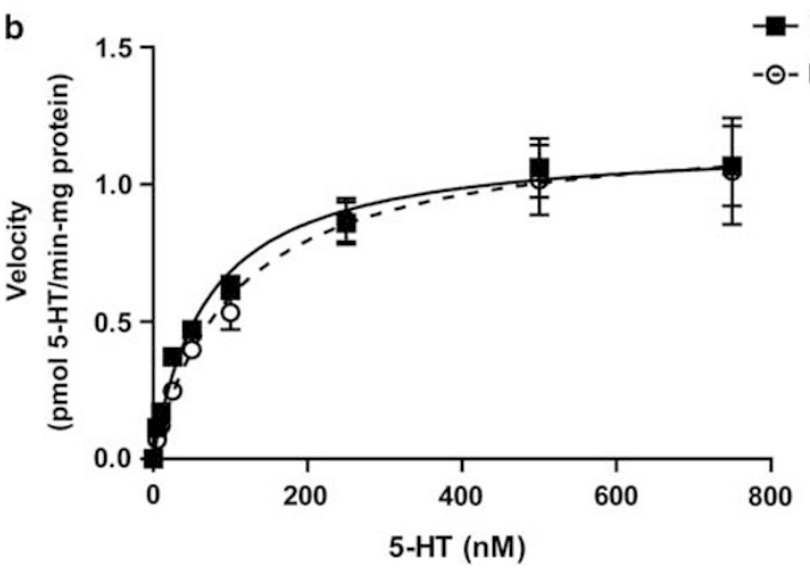

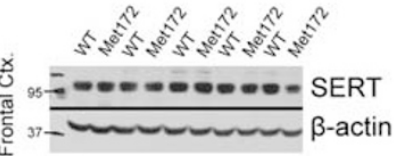
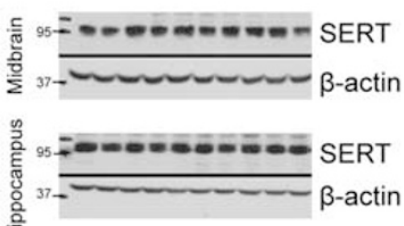
- Met172
C
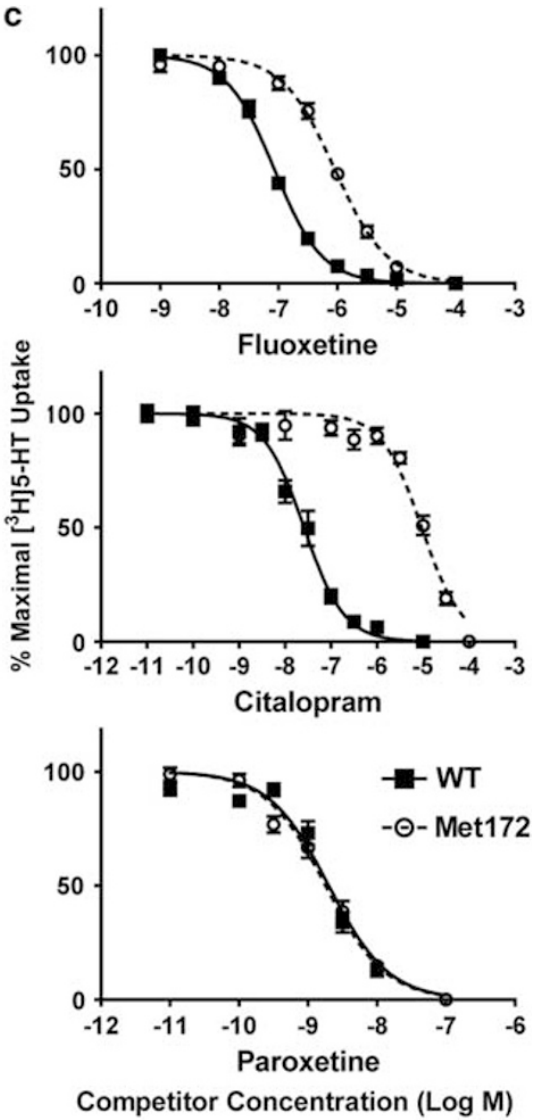

Figure I The SERT MetI72 mutant imposes altered pharmacological sensitivity with normal SERT expression and function. (a) SERT protein expression was measured via western blotting (right), and normalized to $\beta$-actin levels (left). SERT expression did not differ between WT and Met I 72 mice (two-tailed Student's t-test, $P>0.05 ; n=5$ per genotype). (b) Saturation uptake kinetics in WT and SERT Met I 72 whole-brain synaptosomes. WT and Met I 72 do not differ in 5-HT transport activity (WT: $K_{m} 73.04 \pm 15.66 \mathrm{nM} ; V_{\max } 1.18 \pm 0.07 \mathrm{pmol} / \mathrm{min}-\mathrm{mg}$ protein; Met I 72: $K_{\mathrm{m}} 102.0 \pm 24.6 \mathrm{I} \mathrm{nM;} V_{\max } 1.22 \pm 0.09 \mathrm{pmol} / \mathrm{min}-$ mg protein: two-tailed unpaired Student's t-test, $P>0.05, n=6$ per genotype). (c) Competition 5 -HT uptake analysis. Fluoxetine (WT $K_{1}=8.54 \pm 0.02 \times$ $10^{-8} \mathrm{M}$, SERT Met I $72 K_{1}=9.03 \pm 0.03 \times 10^{-7} \mathrm{M}$ ), citalopram (WT $K_{1}=2.07 \pm 0.05 \times 10^{-8} \mathrm{M}$, SERT Met $172 K_{1}=7.91 \pm 0.05 \times 10^{-6} \mathrm{M}$ ), and paroxetine (WT $K_{1}=2.00 \pm 0.03 \times 10^{-9} \mathrm{M}$, SERT Metl $72 K_{1}=1.80 \pm 0.04 \times 10^{-9} \mathrm{M}$ ) were assessed for their ability to compete with $\left[{ }^{3} \mathrm{H}\right] 5-\mathrm{HT}$ uptake. ( $n=4$ per genotype and condition.)

Table I Values Presented as Mean \pm SEM (ng/mg Protein)

\begin{tabular}{|c|c|c|c|c|c|c|}
\hline \multirow[b]{2}{*}{ Substance } & \multicolumn{2}{|c|}{ Frontal cortex } & \multicolumn{2}{|c|}{ Midbrain } & \multicolumn{2}{|c|}{ Hippocampus } \\
\hline & WT & MetI72 & WT & MetI 72 & WT & MetI72 \\
\hline Dopamine & $2.93 \pm 1.90$ & $3.02 \pm 1.19$ & $2.20 \pm 0.15$ & $2.48 \pm 0.11$ & $0.28 \pm 0.05$ & $0.33 \pm 0.07$ \\
\hline Norepinephrine & $5.08 \pm 0.14$ & $5.81 \pm 0.18$ & $8.92 \pm 0.41$ & $10.03 \pm 0.40$ & $6.07 \pm 0.40$ & $6.46 \pm 0.21$ \\
\hline
\end{tabular}

Tissue levels were determined by HPLC-EC analyses as noted in Materials and Methods. Tissue levels of 5-HT, 5-HIAA, dopamine, DOPAC, and norepinephrine did not differ between WT and Met 72 mice ( $n=4$ per genotype, two-tailed Student's t-test). 


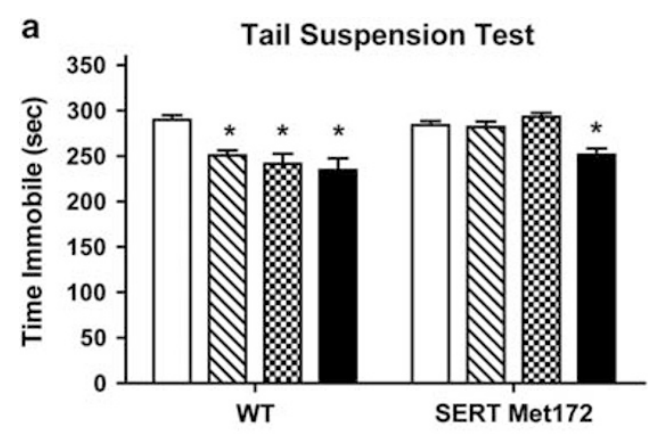

$\square$ Saline $\square$ Fluoxetine $\otimes$ Citalopram $\square$ Paroxetine

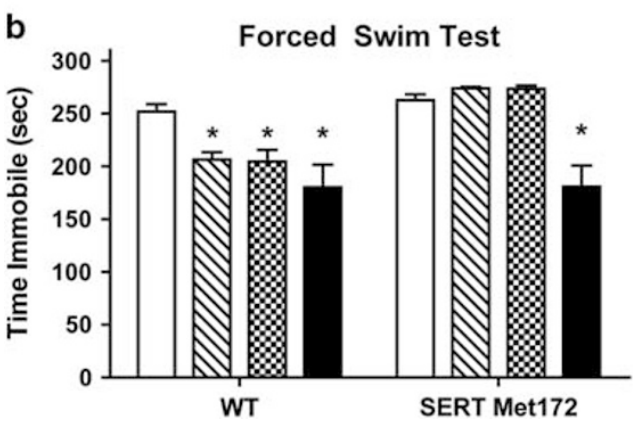

Figure 2 Actions of fluoxetine and citalopram in the TST and FST arise from SERT antagonism. All tests were performed 30 min after i.p. injection of $20 \mathrm{mg} / \mathrm{kg}$ drug. (a) Time immobile in a 6-min TST. Two way ANOVA revealed significant main effects of genotype $(F(I, 72)=17.11, P<0.05)$, treatment $(F(3,72)=10.82, P<0.05)$, and interaction effect $(F(3,72)=4.62$, $P<0.05)$. WT mice display significant decreases in immobility time in response to all drug treatments. Met 72 mice display significant decreases in immobility time only in response to paroxetine. (b) Time immobile in a 6-min FST. Two way ANOVA revealed significant effects of genotype $(F(|, 7|)=18.80, \quad P<0.05)$, treatment $(F(3,7 \mid)=15.92, \quad P<0.05)$, and interaction effect $(F(3,7 I)=4.52, P<0.05)$. WT mice display significant decreases in immobility time in response to all drug treatments. Met 172 mice display significant decreases in immobility time only in response to paroxetine. For $a-b$, * indicates significance $(P<0.05)$ compared with vehicle treatment via Bonferonni post hoc tests $(n=10-12$ per genotype and treatment condition).

\section{The Ability of Chronic Fluoxetine and Citalopram to Promote SGZ Stem Cell Proliferation and Survival is Dependent upon SERT Antagonism}

Hippocampal neurogenesis is a non-behavioral measure of antidepressant efficacy that has been shown to be sensitive to chronic, but not acute, antidepressant administration, and irradiation studies demonstrate neurogenesis as essential for SSRI efficacy in the NIH test (Santarelli et al, 2003). SSRIs promote both hippocampal stem cell proliferation rate and survival of newly generated hippocampal stem cells (Wang et al, 2008). Consistent with these studies, chronic administration of fluoxetine, citalopram, and paroxetine robustly stimulated the proliferation rate (Figure $4 \mathrm{a}$ and $\mathrm{b}$ ) and survival (Figure 4c) of hippocampal stem cells in WT mice, assessed via BrdU+ immunohistochemistry. The magnitude of these elevations in hippocampal neurogenesis measures parallel previous observations (Santarelli et al, 2003). In contrast, only paroxetine was able to enhance hippocampal stem cell proliferation (Figure $4 \mathrm{a}$ and $\mathrm{b}$ ) or survival (Figure 4c) in SERT Met172 mice.
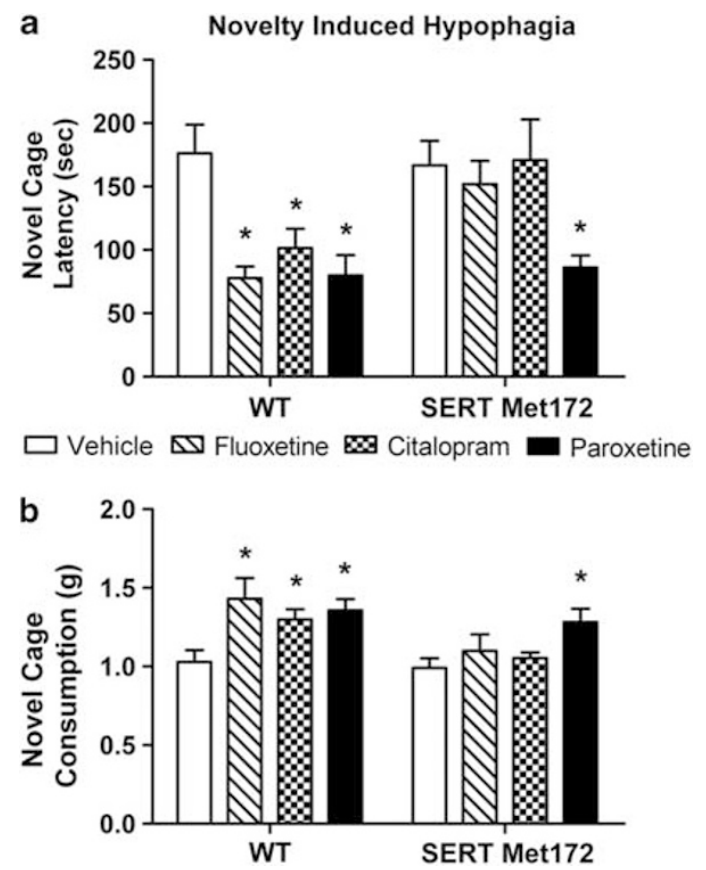

Figure 3 SERT antagonism is required for the chronic effects of fluoxetine and citalopram in the $\mathrm{NIH}$ test. (a) Latency to consume Ensure in novel cage was recorded. Two way ANOVA revealed significant main effects of genotype $(F(I, 97)=4.8 I, P<0.05)$ and treatment $(F(3,97)=5.97$, $P<0.05)$, but not an interaction effect $(F(3,97)=1.92, P>0.05)$. WT mice display significant reductions in latency following chronic SSRI administration, whereas Metl72 mice display significant reductions only following paroxetine administration. (b) Consumption effects: mice were left in novel cage for a total of $30 \mathrm{~min}$ and allowed to freely consume vanilla Ensure. Two way ANOVA revealed significant main effects of genotype $(F(I, 97)=8.53$, $P<0.05)$ and treatment $(F(3,97)=6.10, P<0.05)$, but not an interaction effect $(F(3,97)=1.46, P>0.05)$. WT mice significantly increase consumption following chronic SSRI administration. SERT MetI72 mice only increase consumption following paroxetine administration. For $a-b$, * indicates significance $(P<0.05)$ compared with vehicle treatment Bonferroni post hoc tests $(n=12-18$ per genotype and treatment condition).

\section{DISCUSSION}

The development of SSRIs arose from basic and clinical research that supported a role for 5-HT signaling alterations in depression, and from observations that drugs that increased 5-HT signaling could alleviate depressive symptoms (López-Muñoz and Alamo, 2009). Focusing upon SERT inhibition as a powerful means of 5-HT signal enhancement, multiple SSRIs gained regulatory approval for the treatment of depression and related mood disorders. Although these agents were designed to be SERT specific, a limited capacity to assess the full 'druggable genome' has precluded exclusion of major or minor contributions from other targets. Indeed, multiple proteins have been suggested to interact with various antidepressants with sufficient affinity to warrant further consideration as contributing to antidepressant efficacy (Heurteaux et al, 2006; Saarelainen et al, 2003). In addition, the significant incongruity between the timescale of in vivo SERT antagonism and clinical benefit has raised concerns that other targets may participate, though time-dependent plasticity downstream of 5-HT receptors is a commonly invoked explanation. Indirect 
a

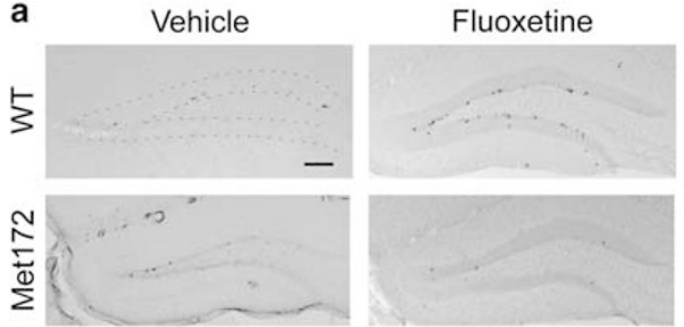

b

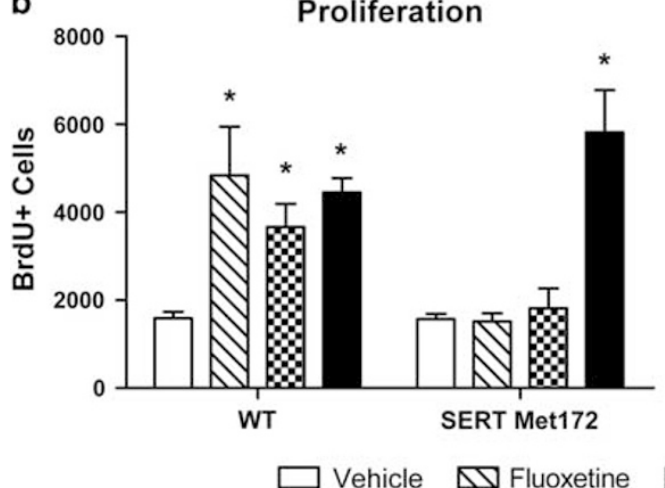

Citalopram

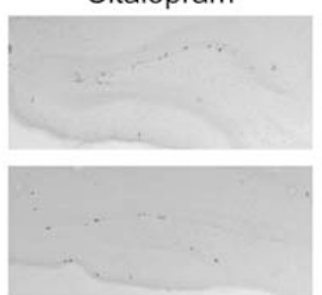

Paroxetine

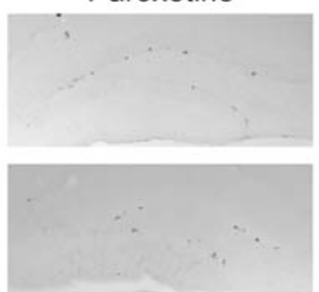

C

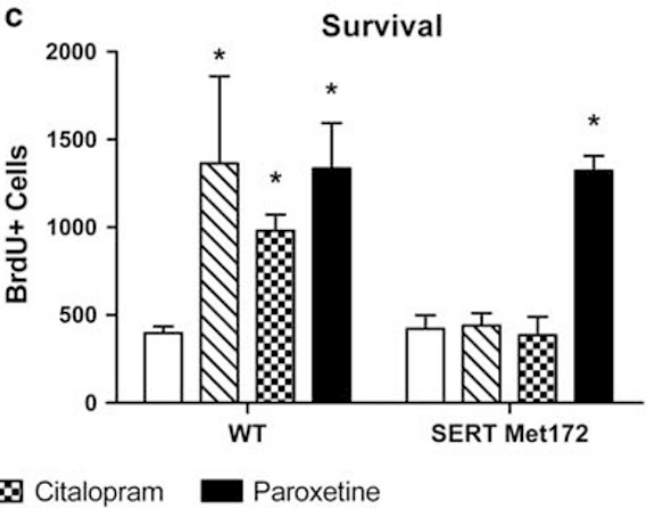

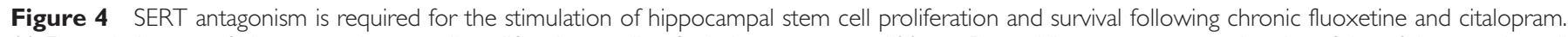

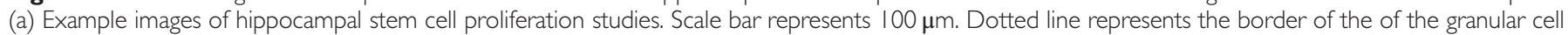

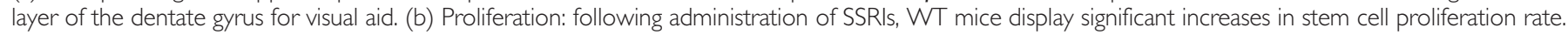

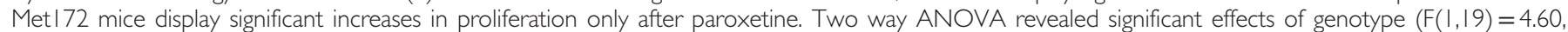

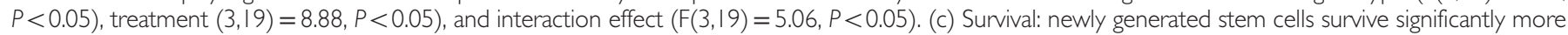

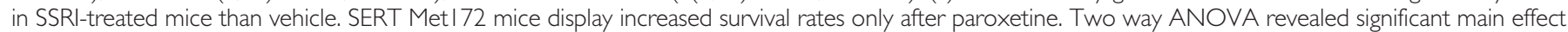

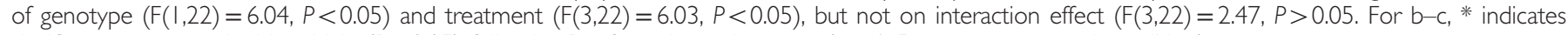
significance compared with vehicle $(P<0.05)$ following Bonferroni post hoc tests $(n=4-5$ per genotype and condition).

support for SERT's primacy in antidepressant action is provided by the existence of multiple, structurally diverse SSRIs that share SERT antagonism but (presumably) differ in off-target actions, as well as the observations that certain 5-HT receptor antagonists can attenuate the effects of SSRIs in preclinical models (Cryan and Lucki, 2000).

Efforts to use SERT KO mice to validate an essential role of SERT blockade in SSRI actions (Holmes et al, 2002) are confounded by the significant compensatory alterations that arise in the model. With these issues in mind, we developed the SERT Met172 mouse model as a potentially powerful tool for extracting the SERT contribution from both SERT-selective and more broadly acting drugs. Our data demonstrate a requirement for SERT antagonism, and by inference, elevations in extracellular 5-HT and 5-HT receptor activation, in both the acute and chronic behavioral actions of the SSRIs fluoxetine and citalopram. We also established that the effects of these drugs in promoting hippocampal stem cell expansion and survival require SERT blockade. Prior in vitro studies with antidepressants found effects on cultured stem cells that lack a serotonergic innervation (Chang et al, 2010), suggesting that SSRIs might have cell autonomous actions on stem cell proliferation and survival. Though our studies do not rule out an auxiliary activity of one or more SSRIs on stem cell proliferation or survival, they indicate that, in vivo, potentiated 5-HT signaling is essential to the well-replicated ability of SSRIs to stimulate subgranular stem cell expansion.
The studies presented in our prior and current reports amply demonstrate the utility of the SERT Met172 model for defining actions of SSRIs as SERT dependent or independent. SSRIs exhibit a number of actions that limit therapeutic benefit, such as effects on libido, weight gain, sleep, and gastrointestinal function that for some individuals can prove unacceptable. Tests that evaluate such actions should benefit from inclusion of the SERT Met172 model to probe their reliance on augmented 5-HT signaling. As observed with paroxetine, however, not all SERT blockers are sensitive to the Met172 substitution, and thus in vitro studies for inhibition of $\left[{ }^{3} \mathrm{H}\right] 5-\mathrm{HT}$ uptake are utilized to assess pharmacological sensitivity before further in vivo assessments. With respect to the utility of the SERT Met172 model in extracting the contribution of 5-HT signaling to mixedaction drugs, we recently capitalized on the model to demonstrate an essential role of SERT blockade in the ability of cocaine to shift circadian rhythms in neuronal firing and locomotor behavior (Prosser et al, 2014). In addition, multiple medications exist that combine SERT inhibition with actions at other targets, including duloxetine, venlafaxine, vortioxetine, and milnacipran. The SERT Met172 model could be helpful in preclinical efforts to determine the degree to which SERT antagonism contributes to the therapeutic efficacy of these agents. Finally, the SERT Met172 model should be of value in elucidating the 5-HT origins of the constellation of molecular plasticities that arise with chronically administered drugs sensitive to the substitution. Using various 'omic' strategies, we envisage exploiting the 
SERT Met172 model to tag molecular changes as SERT dependent or independent, information that can help refine the definition of mechanisms impacting efficacy and treatment onset.

\section{FUNDING AND DISCLOSURE}

Research support was provided by the National Institutes of Health through awards MH094527 (RDB) and MH096972 (RDB and JVV). The Vanderbilt Kennedy Center for Research on Human Development (P30 HD15052) provided infrastructure support for behavioral and neurochemical analyses. Dr Blakely has consulted with Forest, Lundbeck, Wyeth, Pfizer, and Prexa and has received research funding from Forest, Lundbeck, Wyeth, and Prexa. Dr Veenstra-VanderWeele has consulted with Roche, Novartis, and Synapdx, and has received research funding from Roche, Novartis, SynapDx, Seaside Therapeutics, and Forest.

\section{ACKNOWLEDGMENTS}

We thank Tracy Moore-Jarrett for support in backcrossing SERT Met172 mice to the C57BL/6J background and Chris Svitek, Jane Wright, Angela Steele and Qiao Han for excellent laboratory oversight. We acknowledge Gregg Stanwood and John Allison for management of the Vanderbilt Murine Neurobehavioral Laboratory. We also thank Katherine Holleran for technical insights into the NIH test.

\section{REFERENCES}

Arango V, Underwood MD, Gubbi AV, Mann JJ (1995). Localized alterations in pre- and postsynaptic serotonin binding sites in the ventrolateral prefrontal cortex of suicide victims. Brain Res 688: 121-133.

Bengel D, Murphy DL, Andrews AM, Wichems CH, Feltner D, Heils A et al (1998). Altered Brain Serotonin Homeostasis and Locomotor Insensitivity to 3,4-Methylenedioxymethamphetamine ('Ecstasy') in Serotonin Transporter-Deficient Mice. Mol Pharmacol 53: 649-655.

Bianchi MT (2008). Non-serotonin anti-depressant actions: direct ion channel modulation by SSRIs and the concept of single agent poly-pharmacy. Med Hypotheses 70: 951-956.

Byun J, Verardo MR, Sumengen B, Lewis GP, Manjunath BS, Fisher SK (2006). Automated tool for the detection of cell nuclei in digital microscopic images: application to retinal images. $\mathrm{Mol}$ Vis 12: 949-960.

Carneiro AMD, Airey DC, Thompson B, Zhu C-B, Lu L, Chesler EJ et al (2009). Functional coding variation in recombinant inbred mouse lines reveals multiple serotonin transporter-associated phenotypes. Proc Natl Acad Sci USA 106: 2047-2052.

Caspi A, Sugden K, Moffitt TE, Taylor A, Craig IW, Harrington H et al (2003). Influence of life stress on depression: moderation by a polymorphism in the 5-HTT gene. Science 301: 386-389.

Chang E-A, Beyhan Z, Yoo M-S, Siripattarapravat K, Ko T, Lookingland $\mathrm{KJ}$ et al (2010). Increased cellular turnover in response to fluoxetine in neuronal precursors derived from human embryonic stem cells. Int J Dev Biol 54: 707-715.

Cour CM la, Boni C, Hanoun N, Lesch K-P, Hamon M, Lanfumey L (2001). Functional consequences of 5-HT transporter gene disruption on 5-HT1A receptor-mediated regulation of dorsal raphe and hippocampal cell activity. J Neurosci 21: 2178-2185.
Crowley JJ, Blendy JA, Lucki I (2005). Strain-dependent antidepressant-like effects of citalopram in the mouse tail suspension test. Psychopharmacology (Berl) 183: 257-264.

Cryan JF, Lucki I (2000). Antidepressant-like behavioral effects mediated by 5 -Hydroxytryptamine(2C) receptors. J Pharmacol Exp Ther 295: 1120-1126.

David DJ, Samuels BA, Rainer Q, Wang J-W, Marsteller D, Mendez I et al (2009). Neurogenesis-dependent and -independent effects of fluoxetine in an animal model of anxiety/depression. Neuron 62: 479-493.

Dulawa SC, Hen R (2005). Recent advances in animal models of chronic antidepressant effects: the novelty-induced hypophagia test. Neurosci Biobehav Rev 29: 771-783.

Fabre V, Beaufour C, Evrard A, Rioux A, Hanoun N, Lesch KP et al (2000). Altered expression and functions of serotonin 5-HT1A and 5-HT1B receptors in knock-out mice lacking the 5-HT transporter. Eur J Neurosci 12: 2299-2310.

García-Colunga J, Awad JN, Miledi R (1997). Blockage of muscle and neuronal nicotinic acetylcholine receptors by fluoxetine (Prozac). Proc Natl Acad Sci USA 94: 2041-2044.

Gingrich JA, Hen R (2000). Commentary: the broken mouse: the role of development, plasticity and environment in the interpretation of phenotypic changes in knockout mice. Curr Opin Neurobiol 10: 146-152.

Henry LK, Field JR, Adkins EM, Parnas ML, Vaughan RA, Zou M-F et al (2006). Tyr-95 and Ile-172 in transmembrane segments 1 and 3 of human serotonin transporters interact to establish high affinity recognition of antidepressants. J Biol Chemi 281: 2012-2023.

Heurteaux C, Lucas G, Guy N, El Yacoubi M, Thümmler S, Peng X-D et al (2006). Deletion of the background potassium channel TREK-1 results in a depression-resistant phenotype. Nat Neurosci 9: 1134-1141.

Holmes A, Yang RJ, Murphy DL, Crawley JN (2002). Evaluation of antidepressant-related behavioral responses in mice lacking the serotonin transporter. Neuropsychopharmacology 27: 914-923.

Jacobson LH, Cryan JF (2007). Feeling strained? Influence of genetic background on depression-related behavior in mice: a review. Behav Genet 37: 171-213.

Karson CN, Newton JE, Livingston R, Jolly JB, Cooper TB, Sprigg J et al (1993). Human brain fluoxetine concentrations. J Neuropsychiatry Clin Neurosci 5: 322-329.

Kessler RC (2005). Lifetime prevalence and age-of-onset distributions of DSM-IV disorders in the national comorbidity survey replication. Arch Gen Psychiatry 62: 593.

Kessler RC, Chiu WT, Demler O, Walters EE (2005). Prevalence, severity, and comorbidity of 12-Month DSM-IV disorders in the national comorbidity survey replication. Arch Gen Psychiatry 62: 617-627.

Lesch KP, Bengel D, Heils A, Sabol SZ, Greenberg BD, Petri S et al (1996). Association of anxiety-related traits with a polymorphism in the serotonin transporter gene regulatory region. Science 274: $1527-1531$.

Li Q, Wichems C, Heils A, Lesch K-P, Murphy DL (2000). Reduction in the density and expression, but not G-protein coupling, of serotonin receptors (5-HT1A) in 5-Ht transporter knock-out mice: gender and brain region differences. J Neurosci 20: 7888-7895.

Lira A, Zhou M, Castanon N, Ansorge MS, Gordon JA, Francis JH et al (2003). Altered depression-related behaviors and functional changes in the dorsal raphe nucleus of serotonin transporterdeficient mice. Biol Psychiatry 54: 960-971.

López-Muñoz F, Alamo C (2009). Monoaminergic neurotransmission: the history of the discovery of antidepressants from 1950s until today. Curr Pharm Des 15: 1563-1586.

Lucki I, Dalvi A, Mayorga AJ (2001). Sensitivity to the effects of pharmacologically selective antidepressants in different strains of mice. Psychopharmacology (Berl) 155: 315-322. 
Malison RT, Price LH, Berman R, Dyck CH van, Pelton GH, Carpenter L et al (1998). Reduced brain serotonin transporter availability in major depression as measured by [123I]-2 $\beta$ carbomethoxy-3 $\beta$-(4-iodophenyl)tropane and single photon emission computed tomography. Biol Psychiatry 44: 1090-1098.

Mann JJ, Huang Y, Underwood MD, Kassir SA, Oppenheim S, Kelly TM et al (2000). A serotonin transporter gene promoter polymorphism (5-HTTLPR) and prefrontal cortical binding in major depression and suicide. Arch Gen Psychiatry 57: 729-738.

Meyer JH, Wilson AA, Sagrati S, Hussey D, Carella A, Potter WZ et al (2004). Serotonin transporter occupancy of five selective serotonin reuptake inhibitors at different doses: an [11C]DASB positron emission tomography study. Am J Psychiatry 161: 826-835.

Owens MJ, Morgan WN, Plott SJ, Nemeroff CB (1997). Neurotransmitter receptor and transporter binding profile of antidepressants and their metabolites. J Pharmacol Exp Ther 283: $1305-1322$.

Owens M, Nemeroff C (1994). Role of serotonin in the pathophysiology of depression: focus on the serotonin transporter. Clin Chem 40: 288-295.

Paxinos G, Franklin KBJ (2004). The Mouse Brain in Stereotaxic Coordinates. Gulf Professional Publishing.

Porsolt RD, Le Pichon M, Jalfre M (1977). Depression: a new animal model sensitive to antidepressant treatments. Nature 266: 730-732.

Prosser RA, Stowie A, Amicarelli M, Nackenoff AG, Blakely RD, Glass JD (2014). Cocaine modulates mammalian circadian clock timing by decreasing serotonin transport in the SCN. Neuroscience 275: 184-193.

Rioux A, Fabre V, Peter Lesch K, Moessner R, Murphy DL, Lanfumey L et al (1999). Adaptive changes of serotonin 5-HT2A receptors in mice lacking the serotonin transporter. Neurosci Lett 262: $113-116$

Robinson RT, Drafts BC, Fisher JL (2003). Fluoxetine increases GABA(A) receptor activity through a novel modulatory site. J Pharmacol Exp Ther 304: 978-984.
Saarelainen T, Hendolin P, Lucas G, Koponen E, Sairanen M, MacDonald E et al (2003). Activation of the TrkB neurotrophin receptor is induced by antidepressant drugs and is required for antidepressant-induced behavioral effects. J Neurosci 23: 349-357.

Santarelli L, Saxe M, Gross C, Surget A, Battaglia F, Dulawa S et al (2003). Requirement of hippocampal neurogenesis for the behavioral effects of antidepressants. Science 301: 805.

Steru L, Chermat R, Thierry B, Simon P (1985). The tail suspension test: a new method for screening antidepressants in mice. Psychopharmacology 85: 367-370.

Thompson BJ, Jessen T, Henry LK, Field JR, Gamble KL, Gresch PJ et al (2011). Transgenic elimination of high-affinity antidepressant and cocaine sensitivity in the presynaptic serotonin transporter. Proc Natl Acad Sci 108: 3785-3790.

Veenstra-VanderWeele J, Muller CL, Iwamoto H, Sauer JE, Owens WA, Shah CR et al (2012). Autism gene variant causes hyperserotonemia, serotonin receptor hypersensitivity, social impairment and repetitive behavior. Proc Natl Acad Sci USA 109: 5469-5474.

Villard V, Meunier J, Chevallier N, Maurice T (2011). Pharmacological interaction with the sigmal $(\sigma 1)$-receptor in the acute behavioral effects of antidepressants. J Pharmacol Sci 115: 279-292.

Wang J-W, David DJ, Monckton JE, Battaglia F, Hen R (2008). Chronic fluoxetine stimulates maturation and synaptic plasticity of adult-born hippocampal granule cells. J Neurosci 28: 1374-1384.

Warner-Schmidt JL, Vanover KE, Chen EY, Marshall JJ, Greengard P (2011). Antidepressant effects of selective serotonin reuptake inhibitors (SSRIs) are attenuated by antiinflammatory drugs in mice and humans. Proc Natl Acad USA 108: 9262-9267.

Ye R, Blakely RD (2011). Natural and engineered coding variation in antidepressant-sensitive serotonin transporters. Neuroscience 197: 28-36. 